\title{
Effect of hydrostatic pressures on thermoelastic martensitic transformations
}

\author{
D.L. Beke, L. Daroczi, C. Lexcellent ${ }^{1}$ and V. Mertinger ${ }^{2}$
}

Department of Solid State Physics, University of Debrecen, P.O. Box 2, 4010 Debrecen, Hungary

${ }^{1}$ Laboratoire de Mécanique Appliquée Raymond Chaléat, UFR Sciences et Techniques, Université de Franche Comté, 24 chemin de l'Epitaphe, 25030 Besançon, France

${ }^{2}$ Department of Physical Metallurgy, Institute of Material Science, University of Miskolc, 3515 Miskolc-Egyetemváros, Hungary

\begin{abstract}
Supposing that - according to the Clausius-Clapeyron equation - the volume change of the transformation is responsible for the pressure dependence of the equilibrium temperature $T_{0}$, and that the elastic energy term, $e_{0}$, corresponding to the martensite start, $M_{s,}$ (and austenite finish, $A_{f}$ ) temperatures, differs from zero as well, the pressure dependence of the elastic and dissipative energy terms of the martensitic and reverse transformations can be separated. It is illustrated by the example of our experimental results for the pressure effect on the transformations in Cu-22at\%Zn-12at\%Al-1at\%Mn [1] as well as in near equiatomic NiTi shape memory alloys [2]. The elastic energy term, $e_{o}$, showed different behaviour in the low-pressure range for samples of different pre-history, while at high pressures the pressure dependence of the elastic and dissipative terms showed a more general trend.
\end{abstract}

\section{INTRODUCTION}

The basic question in the investigations of the effect of hydrostatic pressure on the martensitic transformations in shape memory alloys is the understanding of the possible shift of the characteristic transformation temperatures i.e. the martensite and austenite start and finish $\left(M_{s}, M_{f}, A_{s}, A_{f}\right)$ temperatures as well as the equilibrium temperature, $T_{0}$ [1-8]. According to the Clausius-Clapeyron equation, the volume change of the transformation is responsible for the shift of To (the temperature where the chemical free energies of the parent and the martensite phase are equal), while the transition temperatures are also sensitive to the details of the nucleation and propagation of martensite in the matrix and thus they also depend on the hardening mechanisms caused by defects (point defects, dislocations or particles) [9]. Thus e.g. $M_{s}$ can show an aging effect as well. Since there is no way for the direct measurement of $T_{0}$ there are different opinions on the best approximation for the estimation of it $[9, \ldots, 12]$.

For the correct thermodynamic description of the transformation, we have to take into account not only the chemical part of the free energy but also the elastic and dissipative energies. The pressure dependence of these non-chemical energies can strongly affect the pressure dependence of the measured transformation temperatures [1,2], but till recently there were no direct experimental evidences for their influence. If we suppose that the shift of the equilibrium transformation temperature, $T_{0}$, is determined by the Clausius-Clapeyron equation and that the volume derivatives of the elastic energy differs from zero at the $M_{s}$ and $A_{f}$ temperatures as well, the pressure dependence of the elastic and dissipative energy terms of the martensitic and reverse transformations can be separated according to the following equations $[1,2]$ :

$$
\begin{aligned}
& \mathrm{M}_{\mathrm{s}}=\mathrm{T}_{0}-\left(\Delta \mathrm{g}_{\mathrm{di}}+\mathrm{e}_{0}\right) /\left(-\Delta \mathrm{s}_{\mathrm{c}}\right) \\
& \mathrm{M}_{\mathrm{f}}=\mathrm{T}_{0}-\left(\Delta \mathrm{g}_{\mathrm{di}}{ }^{*}+\mathrm{e}_{\mathrm{m}}\right) /\left(-\Delta \mathrm{s}_{\mathrm{c}}\right) \\
& \mathrm{A}_{\mathrm{s}}=\mathrm{T}_{0}+\left(\Delta \mathrm{g}_{\mathrm{di}}{ }^{*}-\mathrm{e}_{\mathrm{m}}\right) /\left(-\Delta \mathrm{s}_{\mathrm{c}}\right) \\
& \mathrm{A}_{\mathrm{f}}=\mathrm{T}_{0}+\left(\Delta \mathrm{g}_{\mathrm{di}}-\mathrm{e}_{0}\right) /\left(-\Delta \mathrm{s}_{\mathrm{c}}\right) .
\end{aligned}
$$


Here $\Delta s_{c}<0$ is the entropy change per unit volume of the forward (e.g. from parent to martensite) transformation, $e_{m}$ and $e_{0}$ are the volume derivatives of the elastic energy terms around the $M_{f}$ and $A_{s}$ as well as $M_{s}$ and $A_{f}$ temperatures, respectively. $\Delta g_{d i}{ }^{*}$ and $\Delta g_{d i}$ are the volume derivatives of energies dissipated at the $M_{f}, A_{s}$ and at the $M_{s}, A_{f}$ temperatures, respectively. If $\mathrm{V}_{0}$ is the molar volume of the sample and $\mathrm{V}$ is the volume of the transformed

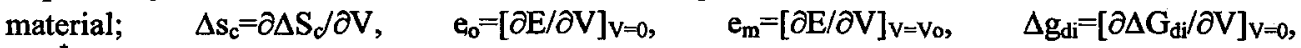

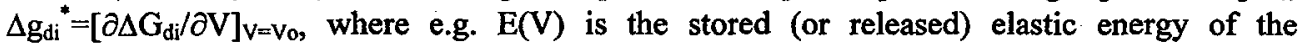
transformation. Thus, supposing that $\Delta \mathrm{s}_{\mathrm{c}}$ is constant (i.e. $\Delta \mathrm{S}_{\mathrm{c}}=\mathrm{V}_{\mathrm{o}} \Delta \mathrm{s}_{\mathrm{c}}$ ) for example the second term of (1) can be written as $V_{o}\left(\Delta g_{d i}+e_{o}\right) / \Delta S_{c}$.

\section{ANALYSIS OF DATA OBTAINED IN CuZnAl AND NiTi ALLOYS}

In both alloys the effect of hydrostatic pressure was investigated by a standard fourpoint resistivity measurements up to $1.5 \mathrm{GPa}$. The volume change and the entropy of transformations were determined at atmospheric pressure by dilatometer as well as from DSC curves taken by a Netsch-204 equipment. For the details of the experiments we refer for [1] and [2]. The compositions of the alloys were $\mathrm{Cu}-22 \mathrm{at} \% \mathrm{Zn}-12 \mathrm{at} \% \mathrm{Al}-1$ at $\% \mathrm{Mn}$ (denoted by $\mathrm{CuZnAl}$ ) as well as Ti-49.5at\%Ni and Ti-49.8at\% Ni (denoted by $J$ and $F$, respectively). Two samples of the same alloy with the same history have been also measured for CuZnAl (and denoted by 1 and 2).

The relative volume changes, the heat of transformations, as well as the entropy changes are shown in Table 1 . The $\mathrm{dT} / \mathrm{dp}$ values calculated from the Clausius-Clapeyron equation; $\mathrm{dT}_{\mathrm{o}} / \mathrm{dp}=\Delta \mathrm{V} / \Delta \mathrm{S}_{\mathrm{c}}$, are also given. Since in NiTi alloys there were two transitions $(\mathrm{B} 2 / \mathrm{R}$ and $\left.\mathrm{R} / \mathrm{B} 19^{\prime}\right)$ the above data are also included for both of these tranformations.

Using equations $(1-4)$ one can easily calculate the ratios of the transformation entropy and the elastic and dissipative energy terms from the experimentally measured transition temperatures as

and

$$
\begin{aligned}
& 1 / 2\left(A_{s}-A_{f}+M_{s}-M_{f}\right)=\left(\Delta g_{d i}{ }^{*}-\Delta g_{d i}\right) /\left(-\Delta s_{c}\right) \\
& 1 / 2\left(A_{s}+A_{f}-M_{s}-M_{f}\right)=\left(\Delta g_{d i}+\Delta g_{d i}\right) /\left(-\Delta s_{c}\right) \\
& 1 / 2\left(-A_{s}+A_{f}+M_{s}-M_{f}\right)=\left(e_{m}-e_{0}\right) /\left(-\Delta s_{c}\right)
\end{aligned}
$$

$$
\begin{aligned}
& 1 / 2\left(M_{s}+A_{f}\right)=T_{0}-e_{0} /\left(-\Delta s_{c}\right) \\
& 1 / 2\left(M_{f}+A_{s}\right)=T_{0}-e_{m} /\left(-\Delta s_{c}\right)
\end{aligned}
$$

as well as

$$
\begin{aligned}
& 1 / 2\left(\mathrm{~A}_{\mathrm{s}}-\mathrm{M}_{\mathrm{f}}\right)=2\left(\Delta \mathrm{g}_{\mathrm{di}}{ }^{*}\right) /\left(-\Delta \mathrm{s}_{\mathrm{c}}\right) \\
& 1 / 2\left(\mathrm{~A}_{\mathrm{f}}-\mathrm{M}_{\mathrm{s}}\right)=2\left(\Delta \mathrm{g}_{\mathrm{di}}\right) /\left(-\Delta \mathrm{s}_{\mathrm{c}}\right) .
\end{aligned}
$$

Table1: Thermodynamical data of transformations in CuZnAl and TiNi alloys

\begin{tabular}{|c|c|c|c|c|c|}
\hline & $\begin{array}{c}\mathrm{Q} \\
(\mathrm{J} / \mathrm{mol})\end{array}$ & $\begin{array}{c}\mathrm{T}_{\mathrm{DSC}} \\
(\mathrm{K})\end{array}$ & $\begin{array}{c}\Delta \mathrm{S}_{\mathrm{c}} \\
(\mathrm{J} / \mathrm{molK})\end{array}$ & $\begin{array}{c}\Delta \mathrm{V} / \mathrm{V} \\
(\%)\end{array}$ & $\begin{array}{c}\mathrm{dT} / \mathrm{dp} \\
(\mathrm{K} / \mathrm{GPa})\end{array}$ \\
\hline $\mathrm{CuZnAl}$ & -352 & 307 & -1.1 & $\cong 0$ & $\cong 0$ \\
\hline J B2/R & -714 & 319 & -3.5 & - & - \\
\hline J R/B19' & -1367 & 253 & -6.4 & - & - \\
\hline F B2/R & -544 & 303 & -3.5 & -0.3 & 14 \\
\hline F R/B19' & -883 & 226 & -5.4 & -0.7 & 24 \\
\hline
\end{tabular}


Functions corresponding to equations (5)-(9) are shown for the two alloys in Fig.1. and Fig. 2. It can be seen that in the range $0.2-1.5 \mathrm{GPa}$ the tendencies are similar in both types of samples for both alloys. On the other hand in the low-pressure range there are relatively strong changes (with considerable scatter), which are even slightly different for the two samples investigated in both cases.

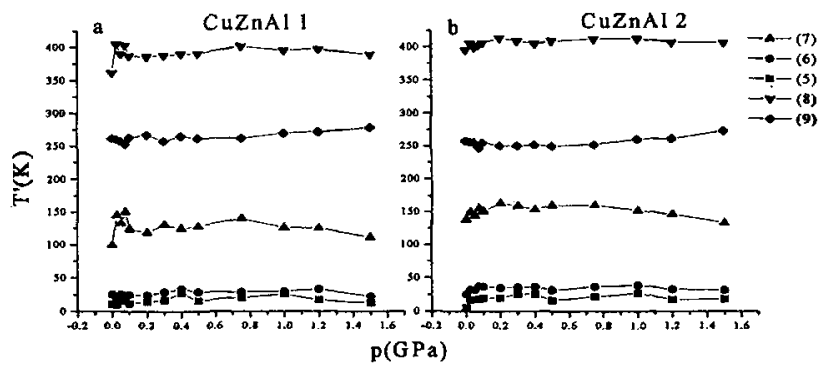

Figure 1 a-b: Terms according to (5)-(9) as a function of pressure for the two CuZnAl samples.

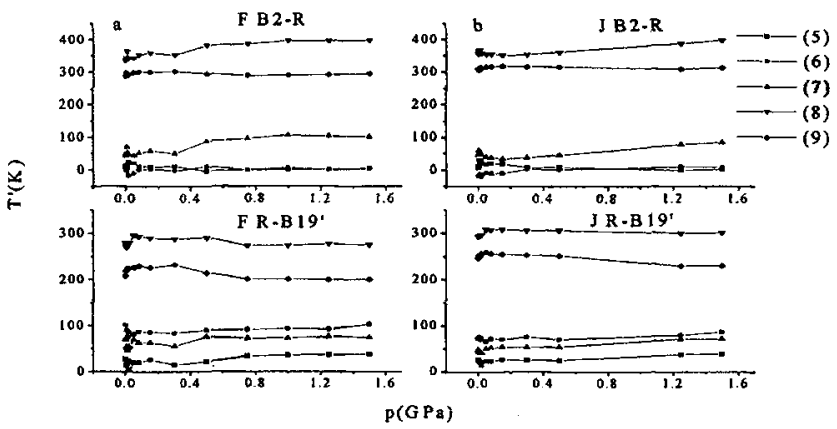

Figure 2 a-b: Terms according to (5)-(9) as a function of pressure for NiTi F and J samples.

Using the data obtained for $\Delta \mathrm{S}_{\mathrm{c}}$ (and supposing that their values are independent of pressure) the elastic and dissipative energy terms can be calculated from equations (5)-(11). Typical energy data at $0.5 \mathrm{GPa}$ are given in Table 2 .

Since the dissipative energy terms can be clearly separated (see eq. (10) and (11)) these are shown as the functions of the pressure in Fig. 3a-b. It can be seen (in Table 2 as well), that in NiTi the dissipative energy terms are approximately zero for the B2/R transition. For the $\mathrm{R} / \mathrm{B} 19^{\prime}$ transition this term is independent of pressure for the forward (i.e. from parent to martensite) transformation. On he other hand the same term for the reverse transformation has again in the pressure range between 0.2 and $1.5 \mathrm{GPa}$ - a definite pressure dependence, the slopes of which are given in Table 2. On the other hand for CuZnAl both dissipative terms are independent of the pressure. 
Table 2: Values of energy terms and their pressure dependence

\begin{tabular}{|c|c|c|c|c|c|c|c|}
\hline & $\begin{array}{c}\mathrm{V}_{0}\left(\mathrm{e}_{\mathrm{m}}-\mathrm{e}_{0}\right) \\
(\mathrm{J} / \mathrm{mol})\end{array}$ & $\begin{array}{c}\mathrm{d}\left(\mathrm{V}_{0} \mathrm{e}_{0}\right) / \mathrm{dp} \\
\left(\mathrm{J} / \mathrm{mol}^{*} \mathrm{GPa}\right)\end{array}$ & $\begin{array}{c}\mathrm{d}\left(\mathrm{V}_{0} \mathrm{e}_{\mathrm{m}}\right) / \mathrm{dp} \\
\left(\mathrm{J} / \mathrm{mol}^{*} \mathrm{GPa}\right)\end{array}$ & $\begin{array}{l}\mathrm{V}_{0} \Delta \mathrm{g}_{\mathrm{di}}^{*} \\
(\mathrm{~J} / \mathrm{mol})\end{array}$ & $\begin{array}{l}\mathrm{V}_{0} \Delta \mathrm{g}_{\mathrm{di}} \\
(\mathrm{J} / \mathrm{mol}) \\
\end{array}$ & $\begin{array}{c}\mathrm{d}\left(\mathrm{V}_{0} \Delta \mathrm{g}_{\mathrm{di}}^{*}\right) / \mathrm{dp} \\
\left(\mathrm{J} / \mathrm{mol}^{*} \mathrm{GPa}\right)\end{array}$ & $\begin{array}{l}\mathrm{d}\left(\mathrm{V}_{0} \Delta \mathrm{g}_{\mathrm{di}}\right) / \mathrm{dp} \\
\left(\mathrm{J} / \mathrm{mol}^{*} \mathrm{GPa}\right)\end{array}$ \\
\hline $\mathrm{CuZnAl}$ & $164 \pm 25$ & $\cong 0$ & -17 & $26 \pm 1$ & $8 \pm 1$ & $\cong 0$ & $\cong 0$ \\
\hline $\mathrm{J} \mathrm{B} 2 / \mathrm{R}$ & 162 & -72 & 63 & $\cong 0 \pm 20$ & $\cong 0 \pm 20$ & $\cong 0$ & $\cong 0$ \\
\hline J R/B19 & 349 & 191 & 266 & 307 & 144 & 90 & $\cong 0$ \\
\hline $\mathrm{FB} 2 / \mathrm{R}$ & 310 & -93 & 90 & $\cong 0 \pm 20$ & $\cong 0 \pm 20$ & $\equiv 0$ & $\cong 0$ \\
\hline F R/B19' & 414 & 208 & 226 & 305 & 185 & 91 & $\cong 0$ \\
\hline
\end{tabular}

In CuZnAl alloys, since $T_{0}$ is independent of pressure $(\Delta V / V \cong 0)$, curves (8) and $(9)$ in Fig.1. reflect the pressure dependence of the elastic terms: there is no observable pressure effect in $e_{o}$, but $e_{m}$ slightly decreases with increasing $p$. On the other hand in NiTi alloys the following procedure can be applied. Supposing that $\Delta V_{d} \Delta S_{c}$ is independent of pressure;

$$
T_{o}(p)=\left(\Delta V_{d} \Delta S_{c}\right) p+T_{o}(o)
$$

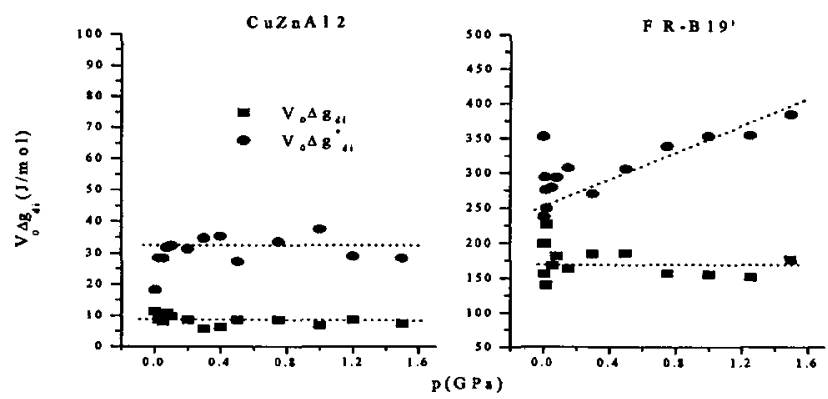

Figure 3 a-b: Pressure dependence of the dissipative energy terms for $\mathrm{CuZnAl}$ (1) and $\mathrm{NiTi}(\mathrm{F})$ samples.

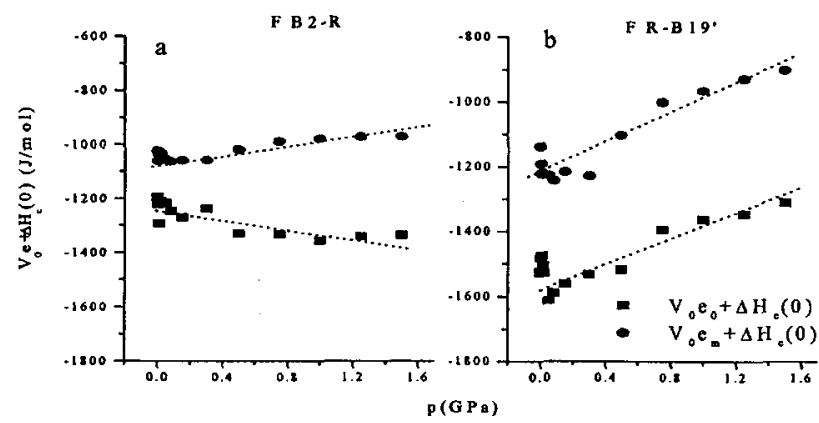

Figure 4 a-b: Elastic energy terms as a function of pressure for NiTi (F) sample. 
Accordingly, replacing $\mathrm{T}_{\mathrm{o}}$ by (12) in (8) as well as (9) the quantities

$$
\begin{aligned}
& V_{o} e_{o}-T_{o}(0)\left(-\Delta S_{c}\right)=V_{o} e_{o}+\Delta H_{c}(0)=\left[-\left(M_{s}+A_{f}\right) / 2+d T_{o} / d p\right]\left(-\Delta S_{c}\right) \\
& V_{o} e_{m}-T_{o}(0)\left(-\Delta S_{c}\right)=V_{o} e_{m}+\Delta H_{c}(0)=\left[-\left(M_{f}+A_{f}\right) / 2+d T_{o} / d p\right]\left(-\Delta S_{c}\right),
\end{aligned}
$$

can be calculated as the function of pressure, where $\Delta \mathrm{H}_{c}(0)=\mathrm{T}_{\mathrm{o}}(0) \Delta \mathrm{S}_{\mathrm{c}}$ is the chemical enthalpy difference between the two phases at $T_{0}(0)$. The curves according to (13) are shown on Fig.4ab. Again the character of these curves are different in the low and high-pressure range. The pressure dependence of the above differences shows a minimum between 0.05 and $0.2 \mathrm{GPa}$. However, the $V_{0} e_{0}+\Delta H_{c}(0)$ curve of the $B 2 / R$ transition is different: in the high-pressure range, there is a slight decrease with increasing pressure. Furthermore, between 0.2 and $1.5 \mathrm{GPa}$ a straight line can be fitted to the curves. They have approximately the same slope for both curves of the $R \rightarrow B 19^{\prime}$ transition, while a smaller slope can be obtained for the $V_{0} e_{m}+\Delta H_{c}(0)$ curve for the $B 2 \rightarrow R$ transition and the slope of the $e_{0}$ term of the $B 2 / R$ transformation is negative(see also Table 2). The ratios of these values and $\Delta S_{c}$ - except the case of $e_{o}$ tfor $B 2 / R$ transition -

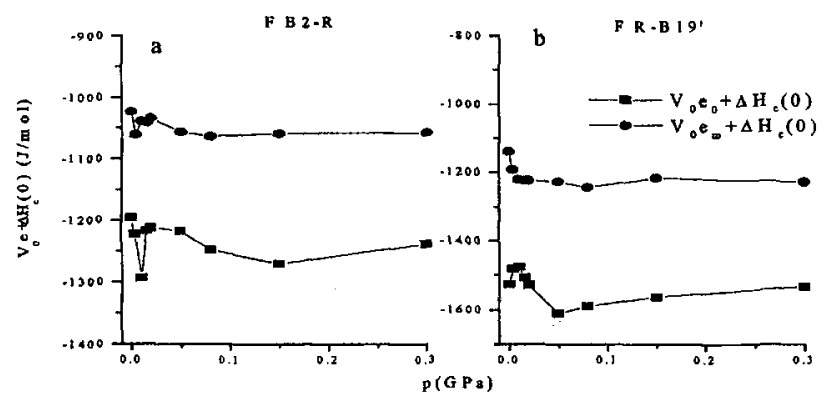

Figure 5 a-b: Pressure dependence of elastic energy terms for NiTi (F) sample in the low pressure range.

have the same order of magnitude than the pressure derivatives of $T_{0}$, derived from the Clausius-Clapeyron equation using the values of $\Delta V_{c}$ and $\Delta S_{c}$ measured. Thus if the supposition $T_{0} \cong 1 / 2\left(M_{s}+A_{f}\right)$ would be used, the pressure dependence of $T_{0}$ would be underestimated from the pressure dependence of the $\mathrm{R} / \mathrm{B} 19^{\prime}$ transition temperatures. Similarly there would be an overestimation for the B2/R transformation (the slope of the $e_{0}$ term is negative, see also (8)) The low-pressure behaviour is shown in Fig.5a-b for NiTi. It can be seen that not only the scatter of the points are large but even the tendencies observed for the two type of samples are different especially for curves corresponding to the $e_{o}$ term. The situation is similar in the $\mathrm{CuZnAl}$ alloys. These observations reflect that the transition temperatures - unlike to $\mathrm{T}_{0}-$ are also sensitive to the details of the nucleation and propagation of martensite in the matrix and thus depend on the hardening mechanisms caused by defects (point defects, dislocations or particles) [9]. Thus e.g. $M_{s}$ can show an aging effect as well as can be slightly different for different samples of the same material, even if they have the same history. Thus it is dangerous to draw any conclusion on the general pressure dependence of the transition temperatures or of $T_{0}$ (if it is estimated from their combinations) from measurements made in a restricted low- 
pressure range. For example in [7] the authors measured only up to $0.025 \mathrm{GPa}$. Thus their results for the pressure dependence of $M_{s}$ can be questionable.

It is also usual in the literature that the pressure derivatives of $M_{s}[8]$ or the "transition temperature" $T_{R}$ (which can be approximated by the arithmetic mean of the start and finish temperatures) [6] are compared to those which can be derived from the volume changes using the Clausius-Clapeyron equation. However, these - because of the possible pressure dependence of the elastic and dissipative energy terms - in general should not be equal to each other, unless a proper analysis does not show that they and their pressure dependence can be neglected.

\section{CONLCUSIONS}

Supposing that - according to the Clausius-Clapeyron equation - the volume change of the transformation is responsible for the shift of the equilibrium temperature $T_{0}$, and that the elastic energy term, $e_{0}$, corresponding to the martensite start, $M_{s}$, (and austenite finish, $A_{f}$ ) temperatures, differs from zero at as well, the pressure dependence of the elastic and dissipative energy terms of the martensitic and reverse transformations could be separated in $\mathrm{CuZnAl}$ and $\mathrm{NiTi}$ alloys. In addition the dissipative terms and their pressure dependence could be directly calculated from the transition temperatures measured. In the high-pressure range both types of energy terms showed linear pressure dependence. In the low-pressure range not only the changes and the scatter of points were relatively large but also the tendencies observed for the two types of samples were different (especially for the $e_{o}$ term) and the differences of the microstructure and history of the samples interpreted it.

\section{References}

[1] L. Daróczi, D.L. Beke, C. Lexcellent, V. Mertinger, Scripta Mater. In press

[2] L. Daróczi, D.L. Beke, C. Lexcellent, to be published

[3] Gefen, Y., Halwany, A., Rosen, M., Phil. Mag. 28, 1 (1973)

[4] Kakeshita, T., Yoshimura, Y., Shimizu, K., Endo, S., Akahama, Y., Fujita, F.E., Trans. Japan Int. Metals 29, 109 (1988)

[5] Kakeshita, T., Shimizu, K., Nakamichi, S., Tanaka, R., Endo, S., Omo, F., Mater Trans. JM 33, 1 (1992)

[6] Kakeshita, T., Saburi, T.,Proceedings of "Solid-Solid Phase Transformations" (Eds. Koiwa, M, Orsuka, K., Miyazaki, T.) The Jap. Inst. of Metals Proc. Vol.12, 1999. P. 907

[7] Johari, G.P. McAnananma, J.G., Sartor, G., Phil. Mag. B74, 243 (1996)

[8] Chernenko, V.A., L'vov, V.A., Phil. Mag. A73, 999 (1996)

[9] Hornbogen, E., Acta metall. 33, 595 (1985)

[10] Funakubo, H. (ed.) Shape memory alloys, Gordon and Breach Science Publ. New York (1986), p.10

[11] Wayman, C.M., Tong, H.C., Scripta Met., 11 (1977) 341

[12] Salzbrenner, R.J., Cohen, M., Acta Met. 27, 739 (1979)

[13] Delaey, L.: Materials Science and Technology, Vol. 5, Phase Transformations in materials, (ed. Haen, P.) VHC, (1991) p. 399

[14] Ortin, J., Planes, A., Acta Metall, 36, 1873 (1988) 